\title{
A Formação de Futuros Professores no Programa Escola Integrada (PEI)
}

The Training of Future Teachers in a Integrated School Program (PEI)

Formación de Futuros Profesores en el Programa Escuela Integrada (PEI)

\section{Roberta Carvalho Romagnoli}

Camila Montandon Dumont Lopes

Faedra Vilaça Ramos

Victória de Paula Roteia Oliveira

Pontifícia Universidade Católica de Minas Gerais (PUC Minas), Belo Horizonte, MG, Brasil

\section{Resumo}

O presente artigo trata dos resultados parciais da pesquisa "Educação Básica e Família: reproduções e invenções no Programa Escola Integrada (PEI) de Belo Horizonte" que objetiva investigar as relações estabelecidas entre estudantes, professores, escolas e família. O PEI é um programa de formação docente implantado e mantido pela Prefeitura Municipal de Belo Horizonte, com base na ampliação da jornada escolar, do qual fazem parte estudantes universitários de diferentes licenciaturas. A metodologia utilizada para abranger a complexidade dessas relações é a pesquisa-intervenção e as ideias de Deleuze e Guattari seu marco teórico. A partir do grupo de estudos feitos em conjunto com os estudantes e os professores supervisores do programa e de entrevistas, analisamos o processo de formação docente, mapeando as linhas duras, flexíveis e de fuga do rizoma PEI. Concluímos que a formação docente é uma experimentação na qual a invenção é necessária resistir à precarização da educação.

Palavras-Chave: Educação Integrada; Pesquisa-Intervenção; Formação Docente.

\begin{abstract}
This article presents the partial results of the research "Basic Education and Family: reproductions and inventions in the Integrated School Program (PEI) of Belo Horizonte" that aims to investigate the relationships established between students, teachers, schools and family. The PEI is a teacher training program implemented and maintained by the Municipality of Belo Horizonte, based on the expansion of the school day, which includes university students from different university courses. The methodology used to cover the complexity of these relationships is the research-intervention and the ideas of Deleuze and Guattari its theoretical framework. From the group of studies made together with the students and the supervising teachers of the program and interviews, we analyze the process of teacher training, mapping the hard, flexible and escape lines of the PEI rhizome. We concluded that teacher training is an experimentation in which invention is necessary to resist the precariousness of education.
\end{abstract}

Keywords: Integrated Education; Research Intervention; Teacher Training. 


\section{Resumen}

Este artículo trata de los resultados parciales de la investigación "Educación Básica y Familia: reproducciones e invenciones en el Programa Escolar Integrado (PEI) de Belo Horizonte", investiga las relaciones establecidas entre los estudiantes, los profesores, las escuelas y la familia. El PEI es un programa de formación de profesores mantenido por la Municipalidad de Belo Horizonte, basado en la ampliación de la jornada escolar, incluyendo a estudiantes universitarios de diferentes grados. La metodología utilizada es la investigación-intervención y las ideas de Deleuze y Guattari su marco teórico. A partir del grupo de estudios realizados junto con los estudiantes y los profesores supervisores del programa y de las entrevistas, analizamos el proceso de formación de los profesores, mapeando las líneas duras, flexibles y de escape del rizoma PEI. Concluimos que la formación de profesores es un experimento en el que la invención es necesaria para resistir la precariedad de la educación.

Palabras Clave: Educación Integrada; Intervención en la Investigación; Formación de Profesores.

\section{Sobre a Educação em Tempo Integral}

A educação é um direito fundamental, que favorece $\mathrm{o}$ desenvolvimento de um país e de cada um de nós, ajuda a combater a vulnerabilidade e diminuir os riscos sociais, além de capacitar os cidadãos com conhecimentos e habilidades. No Brasil, esse direito sempre foi um desafio, inclusive na relação com a própria Psicologia, que foi introduzida na escola dominantemente por meio de um modelo médico/clínico, fundamentado em uma concepção da clínica como um saber/fazer universalizado, associado a uma lógica centrada em um sujeito universal e ahistórico. O respaldo nesse modelo responsabiliza o aluno pelo fracasso escolar, ou seja, pela reprovação e/ou evasão do aluno em algum momento durante $\mathrm{o}$ seu percurso educacional (Oliveira-Menogotto \& Fontoura, 2015). Nessa inserção, para a superação deste modelo reducionista, foram necessários deslocamentos para abordar as implicações institucionais e sociais que atravessam o seu cotidiano. Em um momento no qual somos demandados cada vez mais a colaborar ativamente com a Educação Básica, esse texto destaca a relevância de se atuar na formação docente, desvelando a complexidade das relações de poder que se estabelecem na escola em um programa de tempo integral, revelando suas reproduções e invenções.

A ampliação da jornada escolar no ensino fundamental, bem como as propostas de escola de tempo integral, tiveram seu início na Lei de Diretrizes e 
Bases da Educação Nacional que previa a ampliação progressiva da jornada escolar nessa direção, e, desde então, essa expansão está sendo cada vez mais fomentada pelas políticas públicas. Em 2007, o Governo Federal criou o Programa Mais Educação que designa objetivos de ampliação dos programas de tempo integral na rede pública de ensino e a melhoria de atendimento às necessidades dos alunos, insistindo na oferta de um período escolar de pelo menos sete horas diárias. Nessa direção, em 2014, é implementado o Plano Nacional de Educação, que fixa metas quantitativas para que em dez anos tenhamos no mínimo $50 \%$ (cinquenta por cento) das escolas públicas neste regime (Rezende, Canaan, Reis, Oliveira \& Souza, 2018). Todas essas propostas objetivam o aumento do período no qual os alunos permanecem na escola.

Cabe destacar que a educação em tempo integral tem vários sentidos em nosso país que se diferenciam de acordo com o momento histórico e a proposta. A busca por uma educação integral se inicia nas primeiras décadas do século $\mathrm{XX}$, com pensadores que acreditavam nos projetos educacionais que buscavam o aprofundamento no caráter público da educação escolar. Dentre eles temos o educador Anísio Teixeira e sua concepção da escola nova que tem influenciado as políticas de educação integral em tempo integral no Brasil (Cavaliere, 2010). Para esta corrente, a escola seria um dispositivo essencial para a modernização, com métodos ativos de ensino aprendizagem. Ao valorizar a liberdade e interesse da criança, este dispositivo cria as condições básicas para o aprendizado. A disseminação dos ideais fundados em bases escolanovistas contribuiu para a inserção de novas demandas no pensamento educacional brasileiro contemporâneo, o que resultou na construção de políticas públicas educacionais em uma perspectiva de Educação Integral de Tempo Integral, como vimos acima.

Nesse contexto, Guará (2006) pontua que a educação integral pode ser sintetizada em três formulações. A primeira está relacionada com a educação e sua formação do homem compreendido em sua totalidade, a segunda com a articulação dos saberes e a terceira como a extensão da jornada escolar propondo uma educação integrada para crianças e jovens. Assim, essa extensão na jornada escolar aborda o aluno de forma ampla e diversa, oferecendo diversas ferramentas para sua formação humana. Segundo 
Zapletal e Machado (2019), os defensores dessa ampliação argumentam que a proposta gira em torno de ser sustentada pela cidadania, democracia e qualidade. Alguns fatores contribuem com a ampliação da jornada escolar. Resende e cols. (2018) destacam a busca por melhores resultados e aumento do seu tempo de exposição à ação escolar com a expansão do papel da escola na formação dos alunos, e outros mais amplos, ligados às famílias. Fatores comoa inserção da mulher no mercado de trabalho, a ampla jornada dos pais, os diferentes arranjos familiares com sua singularidade, a condição de vida urbana com todos os seus atravessamentos, fazem com que o grupo familiar reivindique a escola de tempo integral que passa a ser essencial não só para os direitos das crianças e adolescentes, mas também dos trabalhadores e da família.

No entanto, essa medida ainda divide opiniões e suscita críticas quanto à sua funcionalidade. De um lado temos a compreensão de que a ampliação da jornada escolar traz uma melhora e expansão qualitativa do tempo de aprendizagem, enfrentando as desigualdades sociais e educacionais à medida que supre a ausência de oportunidades dessa classe vulnerabilizada e encoraja a participação da comunidade nos espaços escolares. Por outro lado, defende-se que a ampliação seria uma mudança do papel da escola, que antes educava e que se torna apenas um espaço de convivência. Esse argumento acredita que essa implementação é um investimento que poderia ser melhor aplicado na escola de ensino regular e que é ainda uma delegação de responsabilidade do Estado nas escolas. (Zapletal\& Machado, 2019). Certamente a discussão acerca da escola em tempo integral é polêmica e não se dá de forma harmônica.

A partir da demanda nacional de ampliação dos programas de tempo integral na rede pública de ensino para a melhoria da qualidade da educação, no âmbito da formação docente, encontra-se o Programa Escola Integrada (PEI), elaborado pela Prefeitura Municipal de Belo Horizonte (PBH) em 2007. O PEI tem como objetivo assegurar nove horas diárias de atendimento educativo para os alunos, por meio de atividades de acompanhamento pedagógico, cultura, esportes, lazer e formação cidadã. Esse programa associa-se à escola regular, 
voltada para competências intelectuais e aprendizagem de conteúdos escolarizados, oferecendo oficinas de Leitura e Escrita e seus múltiplos usos, Esporte e Lazer, Meio Ambiente e Cidadania, Acompanhamento Pedagógico, Matemática Lúdica e Libras (Barros, 2015). Essas oficinas são realizadas por estudantes das licenciaturas ainda em formação. Além disso, a proposta se sustenta na lógica das "Cidades Educadoras", utilizando espaços naturais e culturais da cidade como extensão da escola para ampliação do conhecimento dos alunos participantes do programa. Assim, o programa favorece as trocas com o território da cidade, pois este movimento, iniciado em 1990 em Barcelona por um grupo de cidades, dentre elas Belo Horizonte, representadas por seus governos locais, para se alcançar uma melhoria da qualidade de vida dos habitantes com participação ativa dos cidadãos.

Neste contexto, esse texto trata dos resultados parciais da pesquisa "Educação Básica e Família: reproduções e invenções no programa Escola Integrada de Belo Horizonte" financiada pelo CNPq e que, nesse recorte tem como objetivo analisar as relações estabelecidas pelos coordenadores e alunos em formação docente nas oficinas do PEI da PUC Minas em convênio com a
PBH, enfatizando a articulação entre estes, a escola e as famílias, com o intuito favorecer a invenção de novas formas de expressão nesses grupos. Na tentativa de contribuir para ações potencializadoras nesse território, os resultados parciais desse estudo são apresentados a seguir.

\section{Metodologia}

Este estudo tem como metodologia a pesquisa-intervenção acompanhando a multiplicidade e complexidade das relações entre a equipe de pesquisa, os estudantes do PEI, os professores supervisores, os alunos e suas famílias. Essa metodologia possui orientação institucionalista, articulando também conceitos da Análise Institucional, contudo, priorizamos a sua sustentação pela a Esquizoanálise. Nesse percurso sustentamos a imanência da reprodução, das capturas e endurecimentos desse território, ao mesmo tempo que busca os movimentos de resistência e de invenção nesses encontros. Certamente essa metodologia é uma valiosa ferramenta, justamente por perseguir o coletivo de forças em cada situação se esforçando para não cair nos dogmas positivistas, "neutros" e reducionistas. (Cardoso\& Romagnoli 2019). Problematiza ainda os lugares 
dominantes ocupados por pesquisadores e demais participantes da análise diluindo as hierarquias e domínios presentes, aproximando o pesquisador do campo de pesquisa em um projeto coletivo de trabalho. Nesse sentido, torna-se um ato de resistência e de criação frente à ciência clássica, possibilitando novos rumos e novas linhas trazidas de fora para dentro (Amador, Lazzarotto\& Santos, 2015).

Essa modalidade de pesquisa faz uma oposição à ciência clássica que trabalha com uma coleta e análise de dados objetiva com etapas para se chegar ao conhecimento "verdadeiro". $\mathrm{Na}$ forma dominante de produção de conhecimento, o pesquisador é um estrangeiro no território e deve manter uma postura neutra, e assim, interpretar os dados com sua neutralidade, baseando-se no paradigma moderno fundamentado na razão como discute Veiga-Neto (2002). Essas pesquisas se amparam nos pressupostos modernos, a saber, objetividade, causalidade, sistematização e produtividade - enfatizando a dissociação da produção de conhecimento com a realidade, a separação do sujeito e objeto e a negação da complexidade. Por outro lado, “(...) as ciências nômades assumem a importância da produção de conhecimentos capazes de agregar fluxos, devires, multiplicidades, organizações (dos átomos às pessoas) turbilhionares, curvilíneais e espiraladas, espaços abertos, elementos vagos e anexatos, análise aproximativas e, contudo, rigorosas" (Cardoso \& Romagnoli, 2019, p. 8).

Assim, a pesquisa intervenção trabalha com a imersão do pesquisador no campo de pesquisa, atitude necessária para colocar em um mesmo plano o conhecer e o transformar, sabendo que não há regras prontas. Na verdade, o conhecimento se faz em uma construção com a população pesquisada, produzindo realidades circunstanciais e transitórias, já que não há uma leitura totalizável da realidade, investigando não apenas o que foi dado, mas se interessando pelo novo, pela transversalidade, pelo plano comum, o diferente, pelos processos e suas linhas. Assim, evidencia o compromisso político do pesquisador, afetando e sendo afetado pelo campo de pesquisa, co-construindo com os agentes pesquisados e restituindo os resultados. (Amador e cols., 2015). Pesquisar/intervir é colocar em um mesmo plano teoria e prática, produção de conhecimento e transformação da realidade, construindo em conjunto com a população estudada, o processo de pesquisa, pois “'(...) a prática da investigação não pode ser determinada só 
pelo interesse do pesquisador, devendo considerar também o protagonismo do objeto. A investigação é cuidado ou cultivo de um território existencial no qual o pesquisador e o pesquisado se encontram" (Alvarez \& Passos, 2015, p. 144). Desse modo, cria-se saídas para a problemática trazida pelo campo de pesquisa, de maneira processual.

Essa metodologia nos permite pensar as relações, mais do que os sujeitos/objetos, voltando-se para a dimensão das forças que atravessam essas relações, para o que ocorre entre as famílias, os estudantes, os professores, atentos aos contextos históricos e sociais e às multideterminações da realidade. Permite ainda colocar os professores em formação como pesquisadores de si e da escola, na busca da liberação da vida para que algo se crie e não somente se reproduza. Reproduções e invenções que esperamos rastrear em nosso estudo.

Assim, para conhecer e transformar, trabalhamos com um campo de análise baseado nas ideias de Deleuze e Guattari, no conhecimento e estudo da Educação Básica e seus impasses atuais e também um campo de intervenção formado através de um projeto de trabalho coletivo com a equipe de professores supervisores da PUC Minas e os estudantes que participam do PEI acolhendo as demandas e dificuldades locais e envolvendo discussões acerca do cotidiano da escola e da inserção do PEI na educação e da dimensão da relação com as famílias, a ser trabalhada em um segundo momento.

Estes dois campos se interpenetram a todo instante no percurso do estudo. Tanto é assim que criamos um grupo de estudos com os objetivos de nos aproximar da realidade vivida pelos estudantes, dar visibilidade a suas problemáticas, acolher e trabalhar as questões que os convocavam. Inicialmente ocorreram três encontros (um por mês) no horário após a aula dos cursos de licenciatura, neles trabalhamos textos de psicologia para um maior conhecimento sobre o grupo familiar e sua relação com a escola. Compareceram nesses encontros alunos de psicologia, a professora responsável pela pesquisa, alunos e professores das licenciaturas. Após esse período, mudamos para um formato quinzenal, no dia dedicado à formação dos alunos do PEI, pois eles têm supervisão sob responsabilidade dos professores da PUC Minas. Nesses encontros compareceram esses alunos, as bolsistas de iniciação científica do curso de psicologia, quatro docentes, um professor do curso de história, uma professora do curso de geografia, uma professora da pedagogia e a 
professora do curso de psicologia que está realizando a pesquisa. Em cada encontro trabalhávamos um texto sugerido inicialmente pela professora responsável pela pesquisa, depois de um tempo os outros docentes sugeriram textos que englobassem a temática da educação básica e tivesse relação com a área do conhecimento que o docente leciona. Ao discutirmos os textos, os estudantes oficineiros traziam suas experiências e dificuldades relacionadas à prática no PEI. Cada encontro era seguido de uma memória, bem como de nossas percepções que integravam nosso diário de bordo, instrumento de produção de dados que acompanha os pesquisadores no percurso da pesquisa e nos quais são anotadas situações, episódios, bem como as impressões e sensações das relações com o campo e com o objeto de estudo, com a vida, buscando rastrear as reproduções e invenções do território da pesquisa.

As discussões aqui apresentadas foram feitas de forma coletiva, no grupo de estudos e em três entrevistas semiestruturadas realizadas com os professores supervisores do PEI. Estávamos nos preparando para a restituição dessas análises parciais quando tivemos a notícia que o programa de extensão, parceria de 20 anos com a PUC Minas, seria extinto pela
PMB e que os bolsistas continuariam suas atividades, mas agora como estagiários. A restituição é um elemento metodológico essencial na pesquisa intervenção, pois permite rever as interpretações preliminares da equipe de pesquisa e, além de assegurar que o pacto do trabalho continue ativo entre todos os participantes. A restituição possibilita a sustentação dos sentidos produzidos pelos sujeitos envolvidos na pesquisa (Amador e cols., 2015). Essas leituras são utilizadas como um suporte para a reflexão coletiva. Embora não tenhamos tido a oportunidade de restituir o material das entrevistas para construir esse texto, o grupo de estudos foi um vetor de transformação, no qual estudamos, contamos experiências, pensamos juntos. Entendemos que colocar produções de conhecimento e experiências em associação é produzir reflexões e críticas atuantes. Essa produção é inerente ao questionamento de pressupostos e intervenções através do coletivo, o que, no nosso entender, possibilita colocar em análise as instituições e os processos de subjetivação que constroem seu cotidiano, nesse caso, o cotidiano do PEI e seus efeitos na formação dos futuros professores. 


\section{O PEI e suas linhas}

Para compreender o cotidiano do PEI e seus efeitos na formação dos estudantes partimos do conceito de rizoma, que, segundo a Esquizoanálise, significa rede de conexões e movimentos. Conforme Deleuze e Guattari (1995), essa rede não tem início e nem fim, não remete a uma unidade, mas se constrói por agenciamentos com os mais variados elementos da realidade, aos quais se conecta a todo instante, não se reportando a uma única combinação ou a uma totalidade. Essa dinâmica de autoprodução é incessante, remetendo ora a forma, fixações, ora a forças/fluxos, agenciamentos que não têm forma e nem limites pré-determinados. O rizoma é composto por linhas, que têm funcionamentos distintos: as linhas de segmentaridade dura, as linhas de segmentaridade flexível e as linhas de fuga (Deleuze \& Parnet, 1998).

As linhas de segmentaridade duras compõem o plano de organização, em um funcionamento binário que separa e classifica: ou se é aluno ou se é professor, ou se é bolsista ou se é supervisor. Essas linhas não consideram as variações, pois são linhas de ordem e de estabilidade atuando a partir de um princípio de fixação, de estancamento da vida em determinadas formas e modelos. $\mathrm{Na}$ sua vida social o homem é segmentarizado em todas as superfícies pelas quais desliza, de maneira visível e molar. As linhas de segmentaridade flexível já envolvem uma mudança de ritmo, um funcionamento conectivo, localizam-se na interface dos segmentos e do intensivo, das forças que deslocam a realidade e as subjetividades, possuindo maior fluidez. "Elas traçam pequenas modificações, fazem desvios, delineiam quedas ou impulsos: não são, entretanto, menos precisas; elas dirigem até mesmo processos irreversíveis" (Deleuze \& Parnet, 1998, p. 101). Por outro lado, as linhas de fuga, ativas e positivas, permitem a saída dos segmentos duros, buscando fazer passar forças nas formas cristalizadas constituindo o plano de consistência. São linhas de ruptura, de mudanças bruscas, muitas vezes imperceptíveis. Seu princípio é o da experimentação e precisam ser inventadas. As linhas traçam acontecimentos, processos inéditos, pois “(...) é sempre sobre uma linha de fuga que se cria, não, é claro, porque se imagina ou se sonha, mas, ao contrário, porque se traça algo real, e compõe-se um plano de consistência. Fugir, mas fugindo, procurar uma arma." (Deleuze \& Parnet, 1998, p. 110) 
Todas essaslinhas fazem parte do rizoma e em algumas situações operam para homogeneizar, formando territórios, ordenando a realidade, em outras, promovem conexões e fogem ao que estava estabelecido. Nesse sentido, podemos dizer que "Existem estruturas de árvore ou de raízes nos rizomas, mas, inversamente, um galho de árvore ou uma divisão de raiz podem recomeçar a brotar em rizoma." (Deleuze \& Guattari, 1995, 0. 24) denotando uma proposta de apreensão da realidade que sustenta a complexidade e o movimento da vida. Esses dois funcionamentos compõe a realidade de modo imanente, justaposto colocando no mesmo plano organização e conexão. A sustentação desse plano de imanência é indispensável para se pensar, para se produzir conhecimento, pois esse plano coloca de maneira justaposta e inseparável, a tensão dessas linhas heterogêneas.

Algumas complexidades e tensões são percebidas pelos professores que fazem parte da formação dos estudantes e que se encontram quinzenalmente com eles para supervisionar as oficinas, como aparece na fala de um entrevistado, e é nesse espaço em que “(...) esses alunos, bolsistas do PEI, transmitem para a gente o que eles estão fazendo lá e as dificuldades que estão sofrendo, que muitas vezes são dificuldades bem práticas mesmo, sobre o funcionamento do PEI, o espaço e tratamento de relações de poder lá dentro mesmo." Esses encontros atuam para a potencialização desses estudantes, acolhendo não somente os desafios da inserção na escola, mas também promovendo a circulação de afetos que desestabilizam estancamentos, que produzem fissuras nos segmentos endurecidos do território escolar, precarizado e reprodutor de burocracias, ressentimentos e hierarquias. Essas pequenas brechas são potentes e, acompanhando o grupo de estudos, vimos como a supervisão dos estudantes pode atuar como intercessora na relação com as oficinas, com a escola, se fazendo também por contágio, criando novos ritmos, burlando o automatismo e a descrença. A noção de intercessor remete à aposta no "entre", na dimensão relacional e molecular como espaço de criação e invenção. $\mathrm{O}$ intercessor permite abrir-se para a processualidade da vida e não corresponde a algo preexistente, a ser descoberto, mas a algo que deve ser criado a partir dos encontros (Deleuze, 1992). Desse modo, a supervisão atua como um sistema multifacetado e intenso, produzindo imprevisibilidades, trazendo mais questionamentos e invenções do que 
certezas e respostas prontas. É um coletivo que se expande para criar, inventar, estar na escola com vida.

Ao realizar uma cartografia da escola, processo de pesquisa aborda a realidade de maneira rizomática, Molin (2011) pontua como a riqueza das experiências nesse domínio é esvaziada pela inércia administrativa que amarra a produção e a invenção em linhas duras, dissemina mágoas e impotências. Assim, linhas de fuga, muitas vezes são impossibilitadas de serem traçadas. Em nossa pesquisa uma das maneiras dessa inviabilidade se exercer é a alta demanda da instituição aos bolsistas, que atuam muitas vezes como "tapa-buracos", impedindo suas atuações nas oficinas. Um dos estudantes desabafa no grupo: "Tem uma responsabilização do PEI, como se nós tivéssemos que fazer e resolver tudo, como se a escola regular não conseguisse e o PEI servisse de quebra-galho.(Diário de Bordo,21/10/2019)" Nessa tensão, gerada pela dificuldade da escola de exercer adequadamente sua função, os estudantes não têm condições de planejar suas atividades, de colocar em prática as propostas elaboradas na supervisão, como nos diz a professora em sua entrevista: “(...) eles tentam fazer projetos que possibilitem uma reflexão..., mas eles não têm tempo, mesmo que eles planejem o projeto, corre o risco da escola atravessar, trazer outras demandas e aí o projeto fica em segundo plano." Nesse contexto, a formação dos futuros professores e a potência da educação não se torna o foco, mas sim a reprodução do que já está instituído, seja para suprir as ausências dos profissionais, seja para reproduzir o que a escola quer nas oficinas, deixando de lado a invenção.

Outra linha dura que estanca as possibilidades do PEI, como colocado por uma das professoras entrevistadas é “(...) nem sempre as escolas têm um espaço adequado para eles realizarem a oficina deles, muitas vezes eles têm que dividir o espaço com outros oficineiros, e se veem às vezes prejudicados no tempo $\mathrm{e}$ no espaço que é dedicado a oficina deles". Ao discutir a parceria com as Cidades Educadoras, programa que busca trabalhar a cidade com um grande espaço educador, para aprender na cidade e com as pessoas, Cavaliere (2014) destaca, que no Brasil, esta é com frequência em função da ausência de infraestrutura e espaço nos prédios escolares para a ampliação do tempo escolar. Os desafios e riscos são enormes, e no que se refere à realidade do PEI encontramos ressonâncias na crítica dos autores de que muitas vezes a 
ampliação da jornada escolar não vem acompanhada da garantia das condições de trabalho adequadas e nem de infraestrutura.

$\mathrm{Na}$ contramão dessa reprodução, retornando à supervisão, esta emerge como um espaço potencial de formação, já que as situações vivenciadas pelos estudantes no cotidiano do PEI são complicadas, envolvem tensões e angústias e é preciso construir saídas. Nessa direção, as linhas duras do rizoma-escola, se flexibilizam, através da sustentação da alteridade, da diferença do outro sem desqualificá-la, como nos fala uma professora supervisorana entrevista:

E eu acho que meus alunos, acabam privilegiando, fortalecendo uma percepção da sensibilidade, do sensível. Não é só: "cumpri o que fiz, cumpri os conteúdos etc.", eles começam a assimilar: "o que será que a gente tem aqui? Temos que ir até o fim”. Às vezes a sensibilidade, o acolhimento, despertar no outro o interesse já é uma coisa muito boa. Então acho que é isso, eles se tornam mais humanos e... é no sentido de reconhecer a dificuldade do outro, as incoerências do outro...

As linhas de segmentaridade flexível são moleculares e encontram-se na interface entre o que está estratificado e as forças que deslocam a realidade $\mathrm{e}$ as subjetividades. "Essa linha molecular mais maleável, não menos inquietante, muito mais inquietante, não é simplesmente interior ou pessoal: ela também põe todas as coisas em jogo, mas em uma outra escala e sob outras formas, com segmentações de outra natureza, rizomáticas ao invés de arborescentes. Uma micropolítica." (Deleuze \& Guattari, 1996, p. 74). Necessária para o desarranjo de endurecimentos que perpetuam a precariedade do território escolar.

As oficinas pressupõem acolhida, aceitação, criação de vínculos. Como acolher os alunos na escola, se eles mesmos, estudantes do PEI, vivem dificuldades de acolhimento e inserção pela instituição, nesse território? Eles sentem que os professores e a administração escolar frequentemente os depreciam em suas atividades diárias. Reclamam que sofrem muita desqualificação e geralmente são colocados como inferiores em discussões e reuniões escolares. Acreditam que existem preconceitos e por isso os professores não querem ajudá-los a desenvolver as oficinas, mesmo que estejam em um projeto conjunto. Relatam que estes professores dizem que eles não têm nada a ver com o PEI porque fazem parte da escola regular. É preciso lembrar que o 
aumento do tempo escolar é feito através do contraturno, entendido como "complementar", distinto do tempo escolar regular. Nessas relações de poder, esses estudantes são acusados de terem privilégios em suas atividades, porque não estão em uma sala de aula normal, árdua e excessiva, e as oficinas são mais leves e agradáveis.

Em interlocução com as ideias de Pierre Bourdieu cartografamos outras linhas duras existentes no território escolar, sustentadas por relações de poder que se manifestam em formas estratificadas de maneira hierárquica. Para Ortiz (1994), Bourdieu explica essas relações através da noção de espaço social, incorporando a diversidade e discutindo as relações de poder e de desigualdade social. A posição que o sujeito ocupa em seu espaço determina suas ações e o seu modo de expressão na linguagem, denunciando que o espaço social evidencia o habitus. Dessa maneira, para Bourdieu (1984) as tensões dentro de um mesmo espaço social não dizem respeito somente a questões econômicas, mas também a bens culturais. Nas relações de poder presentes na escola, hierarquias existem e o capital cultural das camadas dominantes é prestigiado e serve de instrumento de comparação e repetição com desqualificação de outros bens culturais. Ó (2018) denuncia que o modo dominante da escola em nossa sociedade, se faz pela repetição, na tentativa de igualar as diferenças, homogeneizando os habitus de seus alunos, subordinando os distintos saberes em um padrão rígido, em uma forma de regulação e controle.

Essa conservação social que a instituição escola supervaloriza, juntamente com as rotinas de repetição, muitas vezes tentam barrar a potência e a transformação. Os estudantes percebem essa permanência e se manifestam. Um deles fala de como a escola às vezes prefere criar regras do que ouvir os alunos, pois a regra é para sempre e ouvir dava muito mais trabalho. Outro oficineiro conta sobre como nas escolas integradas há uma ideia de trazer o novo, que é vetada pois lá ainda existem coisas muito antiquadas como a divisão de gênero marcada entre as crianças para a realização de atividades. Isso porque "A galera do magistério é mais engessada (...) a escola se distanciou completamente do educar (...) a escola perdeu o sentido (...) eles querem que a massa continuem sendo sempre massa."(Diário de Bordo,16/09/2019), como manifesta um terceiro estudante. Então, como manter essa abertura para o novo, mesmo depois de estarem nas escolas como professores? 
A busca da reprodução na escola também se dá por violência simbólica, expressada pela linguagem e não pela força física, pelo simbólico, na ânsia de humilhar e depreciar (Bourdieu, 1984). Essa violência simbólica é vivida não somente pelos estudantes do PEI, mas ela também circula nas relações entre os professores, funcionários e alunos. Segundo Cassiano e Furlan (2013, p. 373), “As linhas duras são as linhas de controle, normatização e enquadramento, e através de seus atravessamentos se busca manter a ordem e evitar o que é considerado inadequado a determinado contexto social instituído". Assim, para garantir esse funcionamento, julga-se e desqualifica-se crianças e adolescentes vulneráveis que, sem dúvida, não tiveram os mesmos privilégios de quem nasceu no espaço social dominante, pois eles não viram os mesmos filmes, escutaram as mesmas músicas, nem aprenderam as mesmas línguas. Um dos estudantes da licenciatura de História partilhou uma vivência em que a professora de educação física, que grita muito com seus alunos, os colocou em linha e falou que eles nunca iam ser nada, não sabiam falar português e nunca iam aprender inglês. Com esse relato, fica clara a desqualificação do capital cultural dos alunos por parte da professora, a partir de uma leitura da cultura da classe dominante, por isso é importante estar atento a isso para respeitar a cultura dos alunos. Desse modo, entende-se que os meninos pobres que compõem as escolas públicas brasileiras, são incapazes e inferiores, não tendo assim condições de aprender. Essas operações aparecem várias vezes e de diversas maneiras em nosso campo de intervenção, atemorizando os estudantes que fazem parte do PEI, pois a escola não somente reverbera a violência social, nas comunidades enviesadas pelo tráfico, nas lutas pelas bocas, na miséria produzida por uma sociedade tão desigual como a nossa, mas também produz violência, violência simbólica (Silva \& Silva, 2018). Nesse sentido, um dos estudantes relata que em sua escola, a violência é muito presente e é praticada pelos monitores, pelos professores e até, às vezes, por ele. "É o caminho mais fácil, mas temos que fugir". (Diário de Bordo,16/09/2019)

Acerca da violência simbólica, cabe destacar que somos um país marcado pelo passado escravocrata, que deixou legados não só para os negros, mas também para os brancos que garantem condições de privilégios e de superioridade. Esse passado deixa como herança, hierarquias sociais que se atualizam na contemporaneidade e 
reiteram os distintos lugares ocupados por negros e brancos na sociedade brasileira. Lugares nos quais os brancos, indubitavelmente, possuem vantagens no que se refere ao acesso a recursos materiais e simbólicos. De acordo com Schucman (2014) um dos pilares que camufla esses privilégios é o mito da democracia racial, que circula no imaginário social, no qual não haveria preconceitos e oportunidades diferentes para sujeitos de cor/raça, além de uma harmonia entre diferentes raças. Mas não é isso que vemos no cotidiano escolar apresentado no grupo de estudos, pois o bem cultural das classes dominantes não circula na cultura dos alunos das escolas públicas. Nas escolas, nas oficinas do PEI presenciamos violências simbólicas, com atitudes de julgamento e desqualificação de crianças e adolescentes vulneráveis que, com certeza, não tiveram as mesmas oportunidades que a camada dominante. A partir dos bens culturais da classe dominante e da branquitude, os alunos pobres são tratados como incompetentes e inferiores. Essas concepções circulam nas escolas e muitas vezes fazem os alunos desejarem não estar lá.

Embora essas relações de poder e essas vivências de violência tenham emergido nos relatos dos bolsistas, através de uma lógica binária que coloca estes de um lado e os professores de outro, devemos estar atentos a essa polarização, funcionamento estratificado, para não colocar a escola como vilã e obstruir os percursos rizomáticos dos espaços escolares e das suas relações. Certamente não cabe à escola somente as linhas duras, mas como fazer para que esses estudantes, futuros professores, não corram o risco de naturalizar essa violência e comecem a reproduzi-la em suas salas de aula? Ao estudar os sentidos e significados atribuídos por uma professora iniciante ao seu trabalho e à sua profissão, Cericato (2017) assinala a importância do período de iniciação à docência para a sustentação de posturas futuras e também para a continuação na profissão. É nessa fase que o professor está mais vulnerável ao enfrentamento das dificuldades encontradas no cotidiano da escola, em uma profissão desqualificada socialmente e financeiramente, marcada pela sobrecarga física e emocional. Os extensionistas não são ainda professores, mas um dia serão, e nesse momento o elo mais frágil vivencia experiências que podem ser perpetuadas, já que, como destaca Silva e Silva (2018), os professores não assumem explicitamente a violência e tendem a repetir o que viveram em sua vida escolar, mas dessa vez se 
posicionando como vítima e não como agressor, que muitas vezes o é. "Tem muita gente na escola frustrada, quando falamos nas escolas sobre o bom tratamento tratam essa ideia como uma utopia"(Diário de Bordo,02/09/2019), uma vez que é mais fácil se acomodar, não refletir, não mudar sua forma de funcionamento e sim apenas reproduzir este ciclo, pontua um aluno. Um estudante de pedagogia, ao reclamar da gritaria dos monitores com os meninos, escuta do diretor da escola, "Na pedagogia é tudo muito bonito, mas temos que saber que tipo de criança estamos lidando", nos conta uma das alunas acerca da fala da diretora da escola na qual é bolsista.Essa aluna nos disse que nunca gritou com os meninos, resolve os conflitos que aparecem na oficina através de combinados. Por não utilizar do grito para conter a agitação das crianças, ela ouve comentários do tipo: "vamos ver quanto tempo isso vai durar". (Diário de Bordo,19/08/2019).

Para além desses endurecimentos, o rizoma escolar é composto ainda por linhas de fuga, de rupturas que escapam às linhas de segmentaridade duras e que são agenciadas pelas linhas segmentaridade flexíveis. Em sua cartografia do ambiente múltiplo e facetado da escola, Molin (2011) busca não só suas amarras como vimos acima, mas também suas fugas, suas intensidades e assim sua potência locomotiva, que, em nosso estudo remete aos acontecimentos que ocorrem dentro do PEI, aos afetos dos estudantes, as transformações diárias desse território e tudo que o envolve, inclusive seu poder de transformação. Nessa direção, a rede de relações e encontros que se fazem na escola é entregue à experimentação, ao devir educação em sua capacidade de criar mundos, de fazer pensar, de inventar, liberando as forças das formas, dos modelos instituídos que não param de se reproduzir, lançando os alunos nos dispositivos coletivos das oficinas, na potência da vida, como afirmado em uma entrevista:

“A gente brinca lá no PEI que (...) quem passa pelo PEI é capaz de entrar em qualquer escola, porque assim, é muito, muito variado, porque você vira e fala pro menino: não, então você vai entrar e vai fazer assim, aí ele chega lá o diretor tem um outro pensamento, ele faz de um outro jeito, às vezes o diretor quer fazer o PEI bacana, mas aí o coordenador do PEI fica pegando às vezes no pé dos meninos, implicando. Algumas escolas o menino tem espaço físico para fazer atividade, outras eles 
não têm nem esse espaço físico, então a gente tem que pensar em atividades que não demandam muito espaço físico, né. Então eu acho assim que para um aluno que entra e se preocupa com essas atividades, com o que que vai fazer com os alunos e pensa metodologias, eu falo com eles mesmo, eu falo gente, vocês têm um diferencial assim quando se formar, né porque olha o tanto de coisa que vocês fazem..."

Nessas atividades realizadas pelos alunos é que novas composições se fazem no enfrentamento dos conflitos distantes da violência. A construção de saídas impensadas einventivas é feita com os alunos nas oficinas, como por exemplo, uma estudante usa um cartaz escrevendo o que ninguém gosta que o outro fale (em vermelho) e o que gostam (em verde). Outro bolsista sustenta a aceitação das brigas para que eles possam resolver, estando junto dos alunos e sabendo que a violência faz parte do seu cotidiano. Acredita que não adianta ficar "por cima" e fingir que não tem nada acontecendo. $\mathrm{Na}$ oficina de música, trabalha-se funk, e não o que a diretora gostaria, dando voz ao que os alunos querem escutar, como forma de resistência e de valorização da cultura deles. Pequenas situações que dissolvem as hierarquias e possibilitam agenciamentos outros para que o aprendizado aconteça.

Ao problematizar a formação de professores, Gatti (2017) indica a necessidade de estarmos atentos às condições societárias, multifacetadas e heterogêneas, o que nos leva a indagar qual a finalidade da formação e a apostar em compromissos ético e sociais. Nesse contexto, um dos pontos que é o reconhecimento das diferenças, que podem se expressar pela diversidade de costumes, de religião, de gosto musical, de ritos, dentre outros. "As situações geradas no ambiente escolar, e aí vividas, pedem novas compreensões para orientação de ações e relações interpessoais e educativas (professores-alunos-pais; professoresprofessores; $\quad$ professores-gestores; funcionários-alunos; gestores-alunos-pais, etc.), e, sobretudo, novas posturas didáticas e formas diversificadas nas relações pedagógicas. Novas situações, novas respostas." (Gatti, 2017, p. 727)

Para Deleuze e Guattari (1996) essas novas situações são engendradas por linhas de fuga que podem ser traçadas nos territórios mais duros, "Como se uma linha de fuga mesmo que começando de um minúsculo riacho, sempre corresse entre os segmentos, escapando de sua centralização, furtando-se à sua 
totalização. (p. 94).” As linhas de fuga operam por transversalidade, e em no percurso percorrido em nossa pesquisa, colocam o grupo de estudos como um dispositivo produtor de novas realidades, resistindo à reprodução de hierarquizações para que encontros potentes se efetuem, e (trans)formam tanto os estudantes quanto os professores. $\mathrm{Na}$ sustentação das incertezas, novos rumos podem ser traçados e todos aprendem, como colocado por essa professora entrevistada:

“(...) muitas das vezes eu consigo pela prática que eu já tive de educação básica durante quinze anos em escola, mas às vezes eles trazem questões que eu fico assim tão chocada que na hora eu não consigo lidar com aquilo aí eu falo gente eu nunca nem imaginei que isso pudesse existir, uma relação como essa, aí eu tenho que refletir, pensar e depois eu devolvo pra eles ou uma resposta ou uma própria reflexão, que nem sempre a gente traz uma resposta né, é... então pra mim também é desafiador assim, sabe?! Me faz repensar a minha prática como professora, de às vezes ouvir os meninos falando umas coisas que eles não gostam e aí você fala "caramba, né, será então que eu também tenho que repensar isso a'́,, então pra mim também é uma excelente formação né?"“

A formação do PEI faz os estudantes refletirem sobre que tipo de professor querem ser, e eles, em sua maioria afirmam que, quando chegarem lá, não querem ser iguais aos professores das escolas em que estão inseridos. Muitos contam como os alunos gostam do PEI. Apesar das críticas, tais como, o caráter assistencialista do programa, a valorização da proteção das crianças em detrimento da educação, dentre outras, esse programa oferece outras experiências para os alunos e ricas oportunidades de aprendizado, como diz professor entrevistado:

"Ah, eu acho que para o aluno que tem essa experiência, não é só uma questão profissional, no sentido de se ter uma disciplina, de poder se preparar. Não é só a obrigação de planejar uma disciplina... A experiência de estar ali com os alunos e conhecer na prática o que é ter uma turma, tentar ensinar alguma coisa pro aluno e como isso nem sempre acontece do jeito que a gente planeja.“ 
A participação no PEI produz deslocamentos subjetivos no encontro com a alteridade, contribuindo, de fato, para a formação do bolsista que um dia será professor e terá que lidar com a complexidade de uma sala de aulacomo afirmaram todos os professores entrevistados. Ao passar por este programa os estudantes ficam mais "(...) desinibidos, eles pensam, eles sabem lidar, fazer uma transposição didática porque lidaram com menino de seis anos, ele tem que falar de um jeito que é diferente de um menino de quatorze, então isso dá pra ele uma expertise que um menino que só fica aqui na formação acadêmica."

Embora importante para a formação e fonte de aprendizado, o PEI é vivido de forma muito distinta pelas escolas, dependendo de como a gestão o apoia. As diferenças entre as direções foram mencionadas várias vezes no grupo de estudo. A escola, instituição pública de ensino, exige não somente um corpo docente capacitado para levar à cabo a aprendizagem, mas também uma direção e um corpo administrativo que garanta a eficiência da instituição. Nesse sentido, ressaltamos a importância da escuta e do diálogo dos gestores para a construção coletiva de processos de trabalho, uma vez que o não apoio da gestão e pode dificultar a inserção dos estudantes do PEI, atravessando o funcionamento das oficinas, de acordo com a professora entrevistada:

"Eu acho que há uma grande dificuldade na escola, na forma como algumas escolas trabalham né, que tem escolas que abraçam o PEI, e aí fazem de tudo, então tem aluno que consegue pegar material na papelaria que tem dentro da escola, no almoxarifado, consegue pegar uma cartolina um papel, um material, disponibilizam um espaço pra eles, (...) então é muito diferente porque a gente faz um planejamento, você vai pra escola e consegue executar... Mas, muitas vezes, pode não acontecer, a gente fazer um planejamento aqui e chega na escola não acontece, porque ou o monitor ou a escola não abraça, tem escolas que entendem o PEI como algo paralelo, como se não fosse do conjunto de uma comunidade escolar ali, o PEI é um algo à parte da escola... Quando a escola entende assim eu fui chegando à conclusão que fica muito difícil... (...) porque às vezes tem alunos que têm uma dificuldade enorme de fazer atividades mais simples possíveis." 
Como vimos, o processo de institucionalização da ampliação da jornada escolar não se dá sem tensionamentos e impasses. Ao estudar as narrativas de professoras que atuam na escola de tempo integral eexaminar as políticas dirigidas ao tempo de formação no cotidiano das escolas, Bragança e Perez (2016) afirmam que mesmo que os documentos instituam práticas educativas, em nosso caso, gerindo o tempo integral, sem dúvida, são os praticantes do cotidiano que a sustentam, que se reinventam, muitas vezes de modo invisível e silencioso. São eles que cultivam a escola e a formação.

\section{Considerações Finais}

Esse texto pretendeu fazer uma análise dos processos em curso na formação de futuros professores, estudantes integrantes do PEI, sustentando parte das linhas que estão presentes nesse contexto, evidenciando as relações de força que atravessam a subjetivação desses estudantes e modos de se inserir no coletivo escolar. No território escolar existem formas e forças, que tentamos rastrear, deslocando para seus processos. Apostamos na formação como processo, como experimentação e na importância da liberdade ético-política para que a precarização da educação se desfaça.

Esse texto foi atravessado não só pela extinção do PEI, com mencionamos na metodologia, mas pela pandemia do Coronavírus. A pesquisa foi interrompida em sua relação como campo de pesquisa e os encontros e a iniciação científica se deram remotamente. A COVID 19 criou linhas de tensão e de imprevisibilidade para todos e, sobretudo para a educação. Estamos diante de uma nova linguagem em que temos que falar pela tela, nosso corpo vira somente uma voz e um rosto, um olhar. Tudo isso traz a necessidade de repensarmos as práticas educativas. Apesar de todas as provocações e imprevistos, a afirmamos a importância do programa e suas implicações para a comunidade escolar, para as famílias e para os estudantes que o integram.

\section{Referências}

Alvarez, J. \&Passsos, E. (2015). Cartografar é habitar um território existencial. Em E. Passos; V. Kastrup; L. Escossia (Orgs.). Pistas do método da cartografia: pesquisaintervenção e produção de subjetividade(pp. 131-149).Porto Alegre: Sulina. 
Cassiano, M., \& Furlan, R.(2013). O

Amador, F. S.; Lazzarotto, G. D. R.; Santos, N. I. S. (2015). Pesquisaragir, pesquisar-intervir, pesquisarinterferir. Revista Polis e Psique, 5(2), 228-248.

Barros, E. B. R. (2015). Desafios e avanços do Programa Escola Integrada com espaço de prática extensionista sob a ótica dos graduandos da PUC Minas. Em R. Fazzi et al (Orgs.). Infâncias e Adolescências:cidadania em construção(pp. 193-217). Belo Horizonte: FUMARC.

Bourdieu, P. (1984) A Economia das Trocas Simbólicas. São Paulo: Perspectiva.

Bragança, I. F. de S. \& Perez, J. G. de M. (2016). Formação Continuada em Escolas de Tempo Integral: narrativas de professoras. Educação \& Realidade, 41(4), 1161-1182.

Cardoso, M. L. M. \& Romagnoli, R. C. (2019). Contribuições da cartografia para a produção de uma ciência nômade. Polis e Psique. 9(3), 6-25. processo de subjetivação segundo a esquizoanálise. Psicologia \& Sociedade, 25(2), 373-378.

Cavaliere, A. M. (2010). Anísio Teixeira e a educação integral. Paidéia (Ribeirão Preto), 20(46), 249-259.

Cavaliere, A. M. (2014). Escola Pública de Tempo Integral no Brasil: filantropia ou política de estado?Educação $e$ Sociedade, 35 (129), 1205-1222.

Cericato, I. L. (2017). Sentidos e Significados da Docência, segundo uma Professora Iniciante. Educação \& Realidade, 42(2), 729-746.

DELEUZE, G. (1992). Conversações. Rio de Janeiro: Ed. 34.

Deleuze, G. \& Guattari, F. (1995). Introdução: rizoma. Em G. Deleuze \& F. Guattari. Mil Platôs: capitalismo e esquizofrenia (v. 1, pp. 11-37). Rio de Janeiro: Ed. 34

Deleuze, G. \& Guattari, F. (1996). Micropolítica e segmentaridade. Em G. Deleuze \& F. Guattari. Mil Platôs: capitalismo e esquizofrenia 
(v. 3, pp. 83-115). Rio de Janeiro: Ed. 34 .

Deleuze, G. \& Parnet, C. (1998). Diálogos. São Paulo: Escuta.

Gatti, B. A. (2017). Formação de professores, complexidade e trabalho docente. Revista Diálogo Educacional, 17(53), 721-737.

Guará, I. M. (2006). É imprescindível educar integralmente. Cadernos Cenpec, 1(2), 15-24.

Molin, F. D. (2011). Rizomas e fluxos molares e moleculares da máquinaescola: confissões de um cartógrafo. Psicologia \& Sociedade, 23(2), 303311. Recuperado de: http://www.scielo.br/scielo.php?scrip $\mathrm{t}=\mathrm{sci}$ arttext\&pid=S0102$\underline{71822011000200011 \& \operatorname{lng}=\text { pt\&nrm }=}$ iso

Ó, J. R. (2018). Novos ares e o desgoverno da escola: traçados histórico-

genealógicos e a poética do hoje-amanhã. Arquivos Brasileiros de Psicologia, 70(spe), 06-19.

Oliveira-Menegotto, L. M. de, \& Fontoura, G. P. da. (2015). Escola e Psicologia:
Uma História de Encontros e Desencontros. Psicologia Escolar $e$ Educacional, 19(2), 377-386. Recuperado de: http://www.scielo.br/scielo.php?scrip

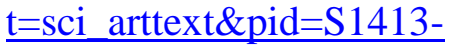
$85572015000200377 \& \operatorname{lng}=\mathrm{pt} \& \mathrm{nrm}=$ iso

Ortiz, R. (1994). Pierre Bourdieu. São Paulo: Ática

Resende, T. de F., Canaan, M. G., Reis, 1. da S., Oliveira, R. A. de, \& Souza, T. C. S. (2018). Dever de Casa e Relação com as Famílias na Escola de Tempo Integral. Educação \& Realidade, 43(2), 435-456.

Romagnoli, R. C. (2017). Transversalizando as políticas públicas: quando a intersetorialidade se torna rizomática. Psicologia em Estudo, 22(3), 421-432.

Silva, M. da, \& Silva, A. G. da. (2018). Professores e Alunos: o engendramento da violência da escola. Educação \& Realidade, 43(2), 471-494. 
Schucman, Lia Vainer. (2014). Sim, nós somos racistas: estudo psicossocial da branquitude paulistana. Psicologia $\&$ Sociedade, 26(1), 83-94.

Veiga-Neto, A. (2002). Olhares. Em M. V. Costa, Marisa Vorraber (Org.). Caminhos investigativos: novos olhares em pesquisa em educação (pp. 23-38) Rio de Janeiro: DP\&A.

Zapletal, P. P.; Machado, A. M. (2019). Ampliação da jornada das escolas públicas brasileiras: um panorama de políticas e discursos. Cadernos CEDES, 39 (08), 209-222.

\section{Roberta Carvalho Romagnoli é} professora no Programa de Pós-Graduação em Psicologia na Faculdade de Psicologia da PUC Minas.

E-mail: robertaroma1@ gmail.com ORCID: https://orcid.org/0000-0003$\underline{3551-2535}$

Camila Montandon Dumont Lopes é graduanda em Psicologia pela PUC Minas. E-mail: camilamontandondumont@gmail.com ORCID: https://orcid.org/0000-0003$\underline{2932-0174}$

Faedra Vilaça Ramos é graduanda em Psicologia pela PUC Minas.

E-mail: faedra.ramos@gmail.com
ORCID: https://orcid.org/0000-0001$\underline{6060-5747}$

Victória de Paula Roteia Oliveira é graduanda em Psicologia pela PUC Minas. E-mail: viroteia@gmail.com

ORCID: $\quad$ https://orcid.org/0000-0002$\underline{1556-3135}$ 